\title{
Autoimmune Gastritis: Distinct Histological and Immunohistochemical Findings Before Complete Loss of Oxyntic Glands
}

\author{
Michael Torbenson, M.D., Susan C. Abraham M.D., John Boitnott M.D., John H. Yardley, M.D., \\ Tsung-Teh Wu, M.D., Ph.D. \\ Division of Gastrointestinal/Liver Pathology, Department of Pathology, The Johns Hopkins University \\ School of Medicine, Baltimore, Maryland
}

Autoimmune gastritis (AG) can be easily recognized when the histological features are fully developed, but recognizing AG before the complete loss of the oxyntic mucosa is more challenging. One feature of fully developed AG is enterochromaffin cell-like (ECL) hyperplasia, but its presence or absence in earlier stages of AG has not been fully evaluated. A retrospective study of biopsy specimens from 40 patients was performed; all of the patients were originally diagnosed with possible $A G$ based on the presence of lymphocytic infiltration and damage to oxyntic glands and/or the presence of metaplastic epithelium that disproportionately involved the body mucosa. Nineteen cases had follow-up serological studies for anti-parietal cells and/or antiintrinsic factor antibodies: 13 were positive and 6 negative. The remaining 21 cases were indeterminate because of incomplete testing. The histological findings were similar in the patients who were serologically positive and those who were indeterminate for AG. In all of these cases, the oxyntic mucosa showed lymphoplasmacytic infiltrates within the lamina propria with focal gland infiltration and damage. Sixty-five percent $(22 / 34)$ of the cases showed intestinal and/or pyloric metaplasia, and 85\% (29/34) showed parietal cell pseudohypertrophy. Chromogranin stains were performed in 11 of 13 cases with positive serological markers for AG, and all showed at least linear ECL cell hyperplasia. In contrast, none of the six cases with negative serological studies had linear ECL cell hyperplasia, $P$ $<.001$. In conclusion, the following constellation of findings supports a diagnosis of AG before the complete loss of oxyntic mucosa: deep or diffuse lym-

Copyright $(2) 2002$ by The United States and Canadian Academy of Pathology, Inc.

VOL. 15, NO. 2, P. 102, 2002 Printed in the U.S.A.

Date of acceptance: October 30, 2001.

Address reprint requests to: Tsung-Teh Wu, M.D., Ph.D., Department of Pathology, Box 85, M.D. Anderson Cancer Center, 1515 Holcombe Boulevard, Houston, TX 77030; e-mail: twu@mdanderson.org; fax: 713-792-4049. phoplasmacytic infiltrates within the lamina propria with foci of gland infiltration and damage, epithelial metaplasia, parietal cell pseudohypertrophy, and ECL cell hyperplasia at the linear or greater level.

KEY WORDS: Autoimmune gastritis, Chromogranin, ECL-cell hyperplasia, Gastrin, Metaplasia, Stomach.

Mod Pathol 2002;15(2):102-109

Autoimmune gastritis (AG) is an inflammatory condition of the stomach that is associated with autoantibodies to parietal cells and intrinsic factor and can lead in a small percentage of patients to destruction of the oxyntic mucosa, pernicious anemia, and the development of carcinoid tumors that are typically indolent. AG is also referred to as Type A gastritis and is recognized as a corpus-restricted atrophic gastritis in the updated Sydney classification system (1). In fully established AG, the body mucosa is inflamed and shows extensive atrophy with replacement of the oxyntic glands by intestinal and pyloric metaplastic epithelium, whereas the antral mucosa is relatively spared. Autoimmune gastritis is often easily recognized when these changes are fully developed and adequately sampled, but earlier manifestations of AG are more challenging to recognize. The following histological features of AG have recently been described in cases without total loss of the oxyntic mucosa $(2,3)$ : (1) a mononuclear infiltrate within the lamina propria that was often heavier in the deep, glandular portions, (2) foci of lymphocytic infiltration and destruction of oxyntic glands, (3) intestinal and/or pyloric gland metaplasia, and (4) pseudohypertrophy of the remaining parietal cells with parietal cell snouting similar to that seen in patients on protonpump inhibitors (PPI). Finally, one third of cases also showed hyperplasia of the enterochromaffin- 
like (ECL) cells using hematoxylin and eosin (H\&E) stains alone (2).

Despite these careful initial descriptions of AG before the complete loss of the oxyntic mucosa, this pattern of gastric injury is frequently underrecognized on endoscopic biopsy specimens. Furthermore, several difficulties can arise when evaluating biopsy specimens for AG. First, none of the above histological features alone are diagnostic. Second, inflamed and partially atrophic mucosa from the antral-oxyntic transitional zone can mimic the patchy atrophy and pyloric metaplasia seen in AG. Third, ECL cell hyperplasia can be difficult to recognize on H\&E stains alone. Therefore, this study was undertaken to evaluate the diagnosis of AG on endoscopic biopsy specimens of body mucosa that still had oxyntic glands. We also employed immunostains for gastrin (a negative stain indicates that the biopsy specimen is truly from the body and not from the antrum or antral-oxyntic transitional zone $(4,5))$ and chromogranin to evaluate for ECL cell hyperplasia.

\section{MATERIALS AND METHODS}

Forty stomach biopsy specimens were retrospectively collected from the time period of January 1991 to August 2000 from the Johns Hopkins Hospital surgical pathology files. All cases still had residual oxyntic mucosa. By customary practice during this time interval, a diagnosis of AG when oxyntic glands were still present was suggested when biopsy specimens showed foci of lymphocytic destruction of oxyntic glands, often accompanied by intestinal and pyloric metaplasia. When the above histological findings were identified, the pathology reports recommended that serological studies be performed for antibodies to parietal cell and intrinsic factor.

Follow-up gastric biopsies were also available for examination in nine patients. The patients' medical records were reviewed for relevant medical history. Patients were classified as positive for AG if serological studies were positive for either anti-parietal cell or anti-intrinsic factor antibodies and negative if both serologies were negative. When neither serological study was available, or when only partial testing was available and was negative, the patients were classified as indeterminate for AG. Serum gastrin levels were also available in a subset of patients and are correlated with the serological status and the chromogranin immunostaining results but were not used to classify individuals as positive or negative for $A G$

Histological sections were obtained from formalin-fixed, paraffin-embedded tissues. The following stains were performed: H\&E, Diff-Quik, pe- riodic acid-Schiff/Alcian blue at $\mathrm{pH}$ 2.5, gastrin (1: 4000 dilution, Zymed Laboratories Inc, San Francisco, CA), and chromogranin (1:4000 dilution, Boehringer Mannheim, Indianapolis, IN). All sections of the antrum and body were evaluated for Helicobacter pylori on Diff-Quik stains. The following histological features were scored on a scale of 0 to $3(0=$ none, $1=$ mild, $2=$ moderate, and $3=$ marked): degree of active inflammation, chronic inflammation, and intestinal and pyloric metaplasia. Pancreatic acinar-type cells were considered to be metaplastic in origin, although others have suggested that they may also represent developmental abnormalities (6). Periodic acid-Schiff/Alcian blue stains were also available and confirmed the presence of intestinal metaplasia. ECL cell hyperplasia in the gastric body was evaluated using chromogranin stains in 35 available cases and was scored as normal, simple, linear, or nodular hyperplasia using the modified Solcia classification schema (7, 8). Briefly, simple hyperplasia showed a mild increase over normal that did not reach the level of linear hyperplasia. Linear hyperplasia was characterized by glands with five or more adjacent chromogranin-positive cells. Nodular hyperplasia was diagnosed when nodular aggregates of at least five chromogranin-positive cells were seen. In the human stomach, gastrin cells are absent from the body mucosa $(4,5)$, and gastrin immunostains were performed in 33 available cases to ensure that the biopsied tissue was from the body.

\section{RESULTS}

\section{Clinical Features}

A total of 40 cases were reviewed, including 27 women and 13 men, with an average age at biopsy of $61 \pm 16$ years (range, 29-84; median, 64 ), with no significant difference in ages between men and women ( $P=.9$; Student's $t$ test). Twenty-six patients were Caucasian, 11 were African-American, 2 were Asian, and 1 was Arabic.

Serological studies allowed classification of patients in 19 cases (Table 1). Of these, 11 patients were positive for parietal cell antibodies and 2 for intrinsic factor antibodies. In one patient, anti-parietal cell antibodies were negative after the index biopsy, but a subsequent biopsy 8 months later again showed changes suspicious for $A G$, and repeat testing was positive at a titer of 1:640. Serum gastrin levels were measured in 15 patients and were elevated in 14, ranging from 165 to 2963 $\mathrm{pg} / \mathrm{mL}$ (normal, <100). Seven of these patients were positive for AG based on serology and had a median serum gastrin level of 581 (range, 212-2963 $\mathrm{pg} / \mathrm{mL}$ ) versus a median serum gastrin level of 120 in two patients classified as negative for AG. The 
remaining six patients were classified as indeterminate for AG and had a median gastrin level of 809 pg/mL (range, 231-1488 pg/mL; Table 1).

Two patients classified as positive for AG had macrocytic anemia at presentation, and two more patients were Vitamin B12 deficient, including one classified as positive and one as indeterminate for AG. Seven of the patients were on PPI at the time of biopsy, including four patients classified as positive for AG and three as indeterminate. The remaining 28 patients were not taking PPI, though an adequate drug history was not available in five cases. Serological studies for $H$. pylori were positive in six cases that were classified as positive $(n=3)$ or indeterminate $(n=3)$ for $A G$ and were negative in one case classified as positive for AG.

Evidence of additional autoimmune disease was present in a total of six female patients classified as positive $(n=3)$ or indeterminate for AG $(n=3)$, two of whom had multiple autoimmune processes: Sjögren's syndrome $(n=3)$, inflammatory peripheral neuropathy $(n=2)$, discoid lupus erythematosus $(n=1)$, overlap syndrome with rheumatoid arthritis and systemic lupus erythematosus $(n=1)$, myasthenia gravis $(n=1)$, and autoimmune hepatitis $(n=1)$. An additional six patients were hypothyroid, including four classified as positive for AG and two as indeterminate. None of the patients had Type I diabetes mellitus, though seven had Type II diabetes mellitus, including three patients classified as positive for AG, three as indeterminate, and one as negative.

\section{Histological Features}

The histological features of the 13 patients with clinically confirmed AG and the 21 patients classified as indeterminate for AG were essentially identical and are combined in the following description. There were two histological features common to all 34 of these biopsy specimens. First, a mild to moderate mononuclear infiltrate composed of admixed lymphocytes and plasma cells was present within the lamina propria and was either diffuse in nature or somewhat heavier in the deeper portions of the mucosa (Fig. 1A; Table 2). Second, all cases showed patchy oxyntic gland infiltration and damage by lymphocytes (Fig. 1B). The remaining histological findings were present in most but not all cases. Parietal cell pseudohypertrophy was seen in 29 (85\%) patients (Fig. 1C), seven of whom were on PPI at the time of biopsy. Metaplastic epithelium was present in $65 \%$ of the cases, including intestinal metaplasia in 16 cases (Fig. 1D), pyloric metaplasia in 16 cases (Fig. 1E), and pancreatic acinar cell metaplasia in 2 cases (Fig. 1F). Mild active inflammation was seen in seven cases. Three of the biopsies were positive for $H$. pylori on Diff-Quik stains.

Gastrin immunostains were negative in all but one case, indicating the biopsies were truly from the oxyntic mucosa. The single positive case was from the indeterminate group, and on review, the biopsy specimen had fragments of both oxyntic and antral-oxyntic transitional mucosa. ECL cell hyperplasia could be identified on H\&E stains in some cases (Fig. 1G). Chromogranin stains were performed in 11/13 cases classified as AG, and all showed at least linear ECL cell hyperplasia (Fig. $1 \mathrm{H})$. One patient had a carcinoid tumor, and a second patient was also found to have a carcinoid tumor on subsequent biopsies. In contrast, only one of six patients with negative serological studies showed ECL cell hyperplasia at the linear level $(P<$ .001 , chi-square test). ECL cell hyperplasia (linear or nodular) was also seen in 13/18 patients classified as indeterminate for AG.

The ECL cell hyperplasia results correlated well with the serum gastrin studies in those patients that were tested. Both elevated serum gastrin levels and at least linear ECL cell hyperplasia were seen in all of the 13 tested patients that were either positive or indeterminate for AG (Table 1). In contrast, serum gastrin levels were either normal or slightly elevated in both of the tested patients classified as negative for AG, and neither had ECL cell hyperplasia at the linear level (Table 1).

TABLE 1. Classification of Patients Based on Serological Study Results along with Available Serum Gastrin Levels

\begin{tabular}{clc}
\hline Classification for & Serological Autoantibodies & Median Serum Gastrin Levels, pg/mL \\
Autoimmune Gastritis & $7(+\mathrm{PC} ;-\mathrm{IF})$ & $581(N=7)$ \\
\hline Positive $(N=13)$ & $1(-\mathrm{PC} ;+\mathrm{IF})$ & \\
& $4(+\mathrm{PC} ; \mathrm{IF}$ not tested $)$ & $120(N=2)$ \\
& $1(+\mathrm{IF} ;$ PC not tested) & $809(N=6)$ \\
Negative $(N=6)$ & $6(-\mathrm{PC} ;-\mathrm{IF})$ & \\
Indeterminate $(N=21)$ & 10 with partial testing & $2(-\mathrm{PC})$ \\
& $6(-\mathrm{IF})$ & 2 (gastrin testing only) \\
& 11 with no testing & \\
\hline
\end{tabular}

PC, parietal cell antibodies; IF, intrinsic factor antibodies. 

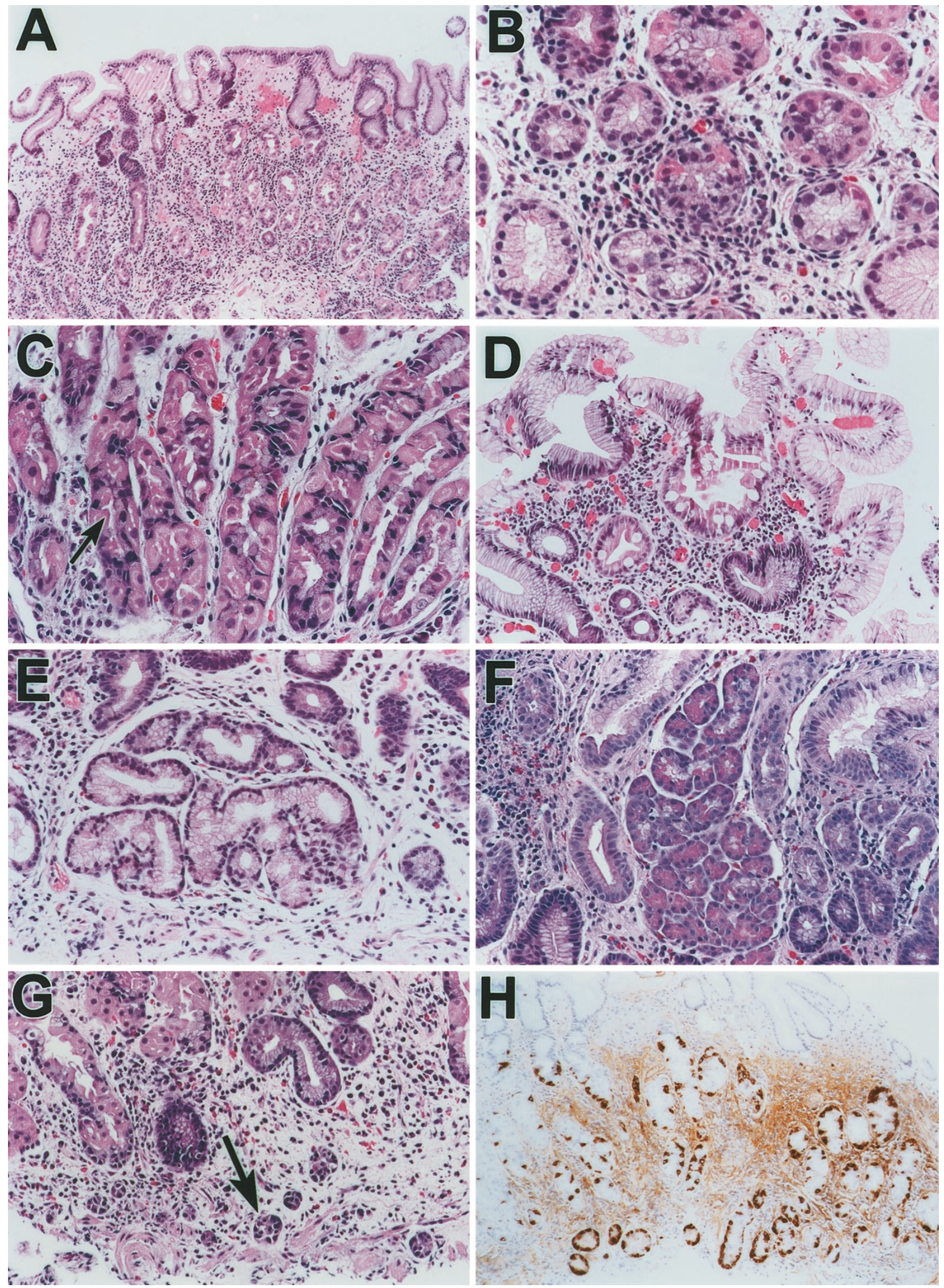

FIGURE 1. Autoimmune gastritis. Diffuse mononuclear infiltrates within the lamina propria that are heavier in the deeper, glandular portions (A). Patchy lymphocytic infiltrates and damage to oxyntic glands (B). Parietal cell pseudohypertrophy with "snouting" resulting from luminal cytoplasmic projections $(\mathbf{C})$. Metaplastic epithelium of the intestinal $(\mathbf{D})$, pyloric $(\mathbf{E})$, and pancreatic acinar types $(\mathbf{F})$. Linear enterochromaffin cell-like cell hyperplasia on hematoxylin and eosin stain $(\mathbf{G})$ and with chromogranin stain $(\mathbf{H})$. 
TABLE 2. Histological Features of Oxyntic Mucosa in Autoimmune Gastritis (AG)

\begin{tabular}{|c|c|c|c|c|c|c|}
\hline Group & $\begin{array}{l}\text { No. of } \\
\text { Total } \\
\text { Cases }\end{array}$ & $\begin{array}{c}\text { Chronic } \\
\text { Inflammation } \\
\text { Grade (Median) }\end{array}$ & $\begin{array}{c}\text { No. of Cases with } \\
\text { Lymphoid } \\
\text { Aggregates/Follicles }\end{array}$ & $\begin{array}{c}\text { No. of Cases with } \\
\text { Parietal Cell } \\
\text { Pseudohypertropy (N) }\end{array}$ & $\begin{array}{l}\text { No. of Cases } \\
\text { with } \\
\text { Metaplasia }^{a}\end{array}$ & $\begin{array}{c}\text { No. of Cases with } \\
\text { Chromogranin } \\
\text { Immunostaining Results }\end{array}$ \\
\hline Positive for $A G$ & 13 & 2 & 7 & 10 & 8,T; 6,I; 7,P & $\begin{array}{l}\text { 5, linear } \\
6 \text {, linear and nodular }\end{array}$ \\
\hline Indeterminate & 21 & 2 & 13 & 19 & 14,T;10,I;9,P & $\begin{array}{l}1 \text {, normal } \\
4 \text {, simple } \\
3 \text {, linear } \\
10 \text {, linear and nodular }\end{array}$ \\
\hline Negative for AG & 6 & 2 & 4 & 2 & $3, \mathrm{~T} ; 3, \mathrm{I} ; 1, \mathrm{P}$ & $\begin{array}{l}\text { 1, normal } \\
4 \text {, simple } \\
1 \text {, linear }\end{array}$ \\
\hline Total & 40 & 2 & 24 & 31 & $25, \mathrm{~T} ; 18, \mathrm{I} ; 17, \mathrm{P}$ & $\begin{array}{l}\text { 2, normal } \\
\text { 8, simple } \\
9 \text {, linear } \\
16 \text {, linear and nodular }\end{array}$ \\
\hline
\end{tabular}

${ }^{a} \mathrm{~T}$, total; I, intestinal; P, pyloric. Any case with intestinal and/or pyloric metaplasia was counted in total category.

On further review of the six cases that were negative for AG based on serological studies, it was noted in retrospect that all but one of these cases lacked the characteristic histological features of AG described above. The most common reason for suggesting AG on the index biopsy specimen was finding intestinal metaplasia that was more prominent in the body than the antrum $(n=3)$ or finding foci of lymphocytic infiltrates within the glandular epithelium $(n=2)$, but with few or none of the other findings to suggest AG. The final case did show most of the histological features of AG, though neither linear nor nodular ECL cell hyperplasia was present. No subsequent biopsies were performed in this individual, and it is not clear whether this last case represents a histological false positive or whether the patient will develop antibodies at some future time.

Follow-up biopsy specimens (from 84 to 2911 days after index biopsy) were available in eight patients classified as positive $(n=5)$ or indeterminate $(n=3)$ for $\mathrm{AG}$, and all showed similar changes suggestive of AG. In another patient classified as negative for $A G$, three follow-up biopsies were available: the first showed an H. pylori infection, but the next two were again interpreted at the time of sign-out as suggestive of AG, based principally on the presence of intestinal metaplasia in the body but not the antrum.

\section{Antral Histology}

The antrum was biopsied in 31 cases (Table 3), and 15 showed features of chemical-bile reflux gastropathy; 10 cases were classified as chronic gastritis; and 6 were classified as chronic active gastritis. All but one of the antral biopsy specimens were negative for $H$. pylori on Diff-Quik stains. Hyperplastic or inflammatory polyps were present in five cases.

\section{DISCUSSION}

Diagnosing AG is often straightforward when the oxyntic mucosa is completely lost and replaced by metaplastic epithelium. However, histologically "earlier" stages of AG, in other words, those before the complete loss of the oxyntic mucosa, can be a diagnostic challenge. Nevertheless, the results from this and other studies $(2,3)$ indicate that a pattern of mucosal injury is strongly suggestive of histologically early AG. Recognition of a pattern of injury is

TABLE 3. Histological Features of Antral Mucosa

\begin{tabular}{|c|c|c|c|c|}
\hline Group & No. Biopsied & Major Histological Finding & $\begin{array}{l}\text { No. of Cases with Lymphoid } \\
\text { Aggregates/Follicles }\end{array}$ & $\begin{array}{l}\text { No. of Cases with } \\
\text { Intestinal Metaplasia }\end{array}$ \\
\hline Positive for AG & 12 & $\begin{array}{l}\text { 4, chemical gastropathy } \\
5 \text {, inactive chronic gastritis } \\
3 \text {, active chronic gastritis }\end{array}$ & 4 & 3 \\
\hline Indeterminate & 19 & $\begin{array}{l}\text { 11, chemical gastropathy } \\
5 \text {, inactive chronic gastritis } \\
3 \text {, active chronic gastritis }\end{array}$ & 3 & 2 \\
\hline Negative for AG & 6 & $\begin{array}{l}\text { 2, chemical gastropathy } \\
4 \text {, inactive chronic gastritis } \\
0 \text {, active chronic gastritis }\end{array}$ & 2 & 1 \\
\hline Total & 37 & $\begin{array}{l}17 \text {, chemical gastropathy } \\
\text { 14, inactive chronic gastritis } \\
6 \text {, active chronic gastritis }\end{array}$ & 9 & 6 \\
\hline
\end{tabular}

AG, autoimmune gastritis. 
important: reliance on one or a few of the histological features in isolation can easily lead to overinterpretation, as demonstrated by six of the cases in this study. This point is further emphasized in Table 2, in which many of the histological features of AG and non-AG, in isolation, show overlap. Also of note, a histologically early stage of $A G$ does not necessarily correlate with early clinical forms of AG, as evidenced by four of the patients in this study who had macrocytic anemia or B12 deficiency at the time of biopsy. In some cases, the histology findings may be the initial clue to a diagnosis of $A G$, as many of the patients may have clinically unrecognized (though clinically present) disease at the time of biopsy, at least in part because patients can present with findings other than the classical macrocytic anemia, such as unexplained microcytic anemia (9).

The results from this and other studies $(2,3)$ highlight the essential inflammatory nature of AG. In this study, lamina propria and glandular infiltrates were found in every case. ECL cell hyperplasia at the linear or greater level was also found in all cases of serologically confirmed AG, suggesting that gastrin levels are often elevated despite the presence of remaining parietal cells. The other histological features were present in most but not all cases, likely reflecting sampling variability and the degree of disease progression. Parietal cell pseudohypertrophy was seen in $85 \%$ of the cases, and metaplastic epithelium was found in $65 \%$ of the cases. In seven of the patients, therapy with PPI also likely contributed to some of the parietal cell pseudohypertrophy and perhaps modestly to elevated serum gastrin levels.

A negative gastrin stain is helpful in ensuring that biopsy specimens from the antral-oxyntic transitional mucosa are not overinterpreted as AG, because the transitional zone can show non-immunemediated chronic inflammation and metaplasia. Gastrin stains are also helpful when a gastric body biopsy specimen shows complete loss of oxyntic mucosa with extensive intestinal and pyloric metaplasia and the differential is autoimmune gastritis versus inadvertent sampling of the antrum.

ECL cell hyperplasia is an integral part of AG. It is present in almost all cases of established AG, is prominent in one third $(10,11)$ and, as shown in this study, can be present before complete loss of the oxyntic mucosa. ECL cell hyperplasia is a direct result of elevated gastrin levels, which are elevated in response to the hypochlorhydria of AG. Hypochlorhydria results from loss of oxyntic mucosa and possibly from the disruption of normal parietal cell maturation (12). The lowered acid secretion leads to increased production of gastrin from the antral G cells, which stimulates ECL cells within the body and can lead to ECL cell hyperplasia. Thus, ECL cell hyperplasia, as well as parietal cell pseudohypertrophy, serve as histological markers of elevated serum gastrin levels. A second mechanism that also contributes to the development of ECL cell hyperplasia is the destruction and atrophy of oxyntic glands, which results in condensation, and coalescence of the spared ECL cells $(3,8)$.

Gastrin-driven ECL cell hyperplasia appears to progress through definable stages: normal, simple hyperplasia, linear hyperplasia, nodular hyperplasia, and beyond (7). The results from this study suggest that at least linear hyperplasia may be a useful marker of AG. Obviously, there must be a progression through simple hyperplasia to reach linear hyperplasia, so the findings of simple hyperplasia are not incompatible with AG and, in fact, have been previously reported (7). Nevertheless, simple hyperplasia is potentially more difficult to interpret, as this level of hyperplasia (and occasionally linear) has been reported in a small percentage of patients on PPI (13-15). Although we employed chromogranin immunostaining to highlight the ECL cells, others have employed the modified Grimelius silver technique (16).

As illustrated by one of the cases in this study, anti-parietal cell antibodies can be initially negative but become positive months later. Interestingly, in a murine model of autoimmune gastritis, the histological gastritis also precedes the development of autoantibodies (17). For this reason, repeat serological testing may be necessary to fully assess for $A G$, especially when subsequent biopsies again show features of AG.

Although the genetic basis in humans is not well understood, linkage analysis in the murine model indicates that susceptibility to AG is associated with a chromosomal region that also confers susceptibility to Type I diabetes mellitus and systemic lupus erythematosus (18). AG in the murine model has also been linked to deficiencies in thyroid hormone (19). In humans, AG has been associated clinically with other autoimmune conditions including Type I diabetes mellitus (20), autoimmune thyroid disease (21), and primary biliary cirrhosis (22).

$H$. pylori infection is the main differential diagnosis for the earlier histological stages of AG when substantial amounts of oxyntic mucosa remain. Therapy with PPI can further complicate interpretation because parietal cell pseudohypertrophy is likely to be seen $(13,14)$. However, most cases can be distinguished by noting the distribution and nature of the inflammatory infiltrate, the distribution of atrophy and metaplasia, the presence of ECL cell hyperplasia at the linear or greater level, and the presence of organisms (Table 4). Although most cases can be classified as AG or as H. pylori infection, these two entities can certainly coexist as seen in three of the cases in this study. In the original 


\begin{tabular}{|c|c|c|}
\hline Feature & AG & H. Pylori Gastritis \\
\hline Nature of inflammatory infiltrate & $\begin{array}{l}\text { Diffuse or patchy lymphoplasmacytic infiltration of } \\
\text { lamina propria, often with deep predominance }\end{array}$ & $\begin{array}{l}\text { Often a bandlike infiltrate that is oriented more } \\
\text { superficially and frequently shows activity }\end{array}$ \\
\hline Gland destruction & Frequent & Infrequent \\
\hline Parietal cell hyperplasia/hypertrophy & Frequent & Infrequent (unless on proton pump inhibitors) \\
\hline ECL cell hyperplasia (at least linear) & Frequent & Infrequent \\
\hline Predominantly affected part of stomach & Body & Antrum and body \\
\hline Predominant location of metaplasia & Body (intestinal/pyloric) & Antrum (intestinal) \\
\hline
\end{tabular}

histological description of AG with remaining oxyntic mucosa, $22.5 \%$ of patients had both AG and $H$. pylori infection (2), and other studies have also noted concurrent AG and $H$. pylori infection (7). Lymphoma of the mucosal-associated lymphoid tissue (MALT) can also occasionally be in the differential diagnosis for AG but can usually be differentiated by the dense, destructive nature of the neoplastic B-cell infiltrates in MALT lymphoma. Immunophenotypic studies of the infiltrates can also be helpful in difficult cases.

The precise relationship between AG and $H$. pylori gastritis remains unclear and controversial, but some studies suggest an association. Many patients with $\mathrm{H}$. pylori gastritis develop autoantibodies, which can include anticanalicular, antifoveoalar, as well as the classic antiparietal cell antibodies. CagAnegative strains of $H$. pylori have been implicated in particular (23). The most common autoantibodies in $H$. pylori-infected patients are anticanalicular and appear to be directed against the $\mathrm{H}+, \mathrm{K}^{+}$ATPase (as are the classic anti-parietal cell antibodies) and are strongly associated with body atrophy. When $H$. pylori organisms are present along with AG, then treatment of the $H$. pylori infection is important and can even reduce the serum gastrin levels and cause regression of the ECL cell hyperplasia, though the atrophic changes do not appear to improve (24).

In conclusion, this study confirms the previously described core histological features of AG that can be recognized before complete loss of the oxyntic mucosa $(2,3)$, and it highlights the usefulness of chromogranin and gastrin immunostains in evaluating for AG. On the basis of results from previous studies $(2,3)$ and the results from this study, the following constellation of histological and immunostain findings are considered to be strongly suggestive of AG before complete loss of the oxyntic mucosa:

1. Patchy to diffuse lymphoplasmacytic infiltrates within the lamina propria that are often heavier in the deeper portion,

2. Focal lymphocytic infiltration and destruction of oxyntic glands,

3. Patchy atrophy of oxyntic mucosa with intestinal and/or pyloric metaplasia,

4. Parietal cell pseudo-hypertrophy,
5. ECL cell hyperplasia, usually of the linear or greater level, and

6. Negative staining for gastrin (important to ensure the biopsy specimen is truly from the gastric body).

It bears emphasis that none of these features are diagnostic in isolation: it is the pattern of findings that suggest AG. Although no specific treatment is available at this time to prevent the progression of AG, an accurate diagnosis can be important in clinical management decisions.

\section{REFERENCES}

1. Dixon MF, Genta RM, Yardley JH, Correa P. Classification and grading of gastritis. The updated Sydney System. International Workshop on the Histopathology of Gastritis, Houston, 1994. Am J Surg Pathol 1996:20:1161-81.

2. Stolte M, Baumann K, Bethke B, Ritter M, Lauer E, Eidt H. Active autoimmune gastritis without total atrophy of the glands. Z Gastroenterol 1992;30:729-35.

3. Eidt S, Oberhuber G, Schneider A, Stolte M. The histopathological spectrum of type A gastritis. Pathol Res Pract 1996; 192:101-6.

4. Stave R, Brandtzaeg P. Immunohistochemical investigation of gastrin-producing cells ( $\mathrm{G}$ cells). The distribution of $\mathrm{g}$ cells in resected human stomachs. Scand J Gastroenterol 1976;11: 705-12.

5. Ohchi T, Misumi A, Akagi M. A study on the distribution of G-cells in human gastric mucosa. Gastroenterol Jpn 1984;19: 41-52.

6. Krishnamurthy S, Integlia MJ, Grand RJ, Dayal Y. Pancreatic acinar cell clusters in pediatric gastric mucosa. Am J Surg Pathol 1998;22:100-5.

7. Bordi C, Annibale B, Azzoni C, Marignani M, Ferraro G, Antonelli G, et al. Endocrine cell growths in atrophic body gastritis. Critical evaluation of a histological classification. J Pathol 1997;182:339-46.

8. Solcia E, Fiocca R, Villani L, Luinetti O, Capella C. Hyperplastic, dysplastic, and neoplastic enterochromaffin-like-cell proliferations of the gastric mucosa. Classification and histogenesis. Am J Surg Pathol 1995;19:S1-7.

9. Marignani M, Delle Fave G, Mecarocci S, Bordi C, Angeletti S, D'Ambra G, et al. High prevalence of atrophic body gastritis in patients with unexplained microcytic and macrocytic anemia: a prospective screening study. Am J Gastroenterol 1999; 94:766-72.

10. Solcia E, Rindi G, Fiocca R, Villani L, Buffa R, Ambrosiani L, et al. Distinct patterns of chronic gastritis associated with carcinoid and cancer and their role in tumorigenesis. Yale J Biol Med 1992;65:793-804; discussion 27-9.

11. Solcia E, Fiocca R, Villani L, Gianatti A, Cornaggia M, Chiaravalli A, et al. Morphology and pathogenesis of endocrine hyperplasias, precarcinoid lesions, and carcinoids arising in 
chronic atrophic gastritis. Scand J Gastroenterol Suppl 1991; 180:146-59.

12. Judd LM, Gleeson PA, Toh BH, van Driel IR. Autoimmune gastritis results in disruption of gastric epithelial cell development. Am J Physiol 1999;277:G209-18.

13. Creutzfeldt W, Lamberts R. Is hypergastrinaemia dangerous to man? Scand J Gastroenterol Suppl 1991;180:179-91.

14. Rindi G, Fiocca R, Humphires T. Argyrophil ECL histology in the gastric corpus and antrum in 243 patients taking Raberprazole $10 \mathrm{mg}$ or $20 \mathrm{mg}$ or Omeprazole $20 \mathrm{mg}$ for one year. [abstract]. Digestion 1998;59(3 Suppl):234.

15. Thjodleifsson B, Beker JA, Dekkers C, Bjaaland T, Finnegan V, Humphries TJ. Rabeprazole versus omeprazole in preventing relapse of erosive or ulcerative gastroesophageal reflux disease: a double-blind, multicenter, European trial. The European Rabeprazole Study Group. Dig Dis Sci 2000; 45:845-53.

16. Lack EE, Mercer L. A modified Grimelius argyrophil technique for neurosecretory granules. Am J Surg Pathol 1977;1: 275-7.

17. Martinelli TM, van Driel IR, Alderuccio F, Gleeson PA, Toh $\mathrm{BH}$. Analysis of mononuclear cell infiltrate and cytokine production in murine autoimmune gastritis. Gastroenterology 1996;110:1791-802.

18. Silveira PA, Baxter AG, Cain WE, van Driel IR. A major linkage region on distal chromosome 4 confers susceptibility to mouse autoimmune gastritis. J Immunol 1999;162:5106-11.
19. Wang J, Griggs ND, Tung KS, Klein JR. Dynamic regulation of gastric autoimmunity by thyroid hormone. Int Immunol 1998;10:231-6.

20. De Block CE, De Leeuw IH, Van Gaal LF. High prevalence of manifestations of gastric autoimmunity in parietal cell antibody-positive type 1 (insulin-dependent) diabetic patients. The Belgian Diabetes Registry. J Clin Endocrinol Metab 1999;84:4062-7.

21. Centanni M, Marignani M, Gargano L, Corleto VD, Casini A, Delle Fave G, et al. Atrophic body gastritis in patients with autoimmune thyroid disease: an underdiagnosed association. Arch Intern Med 1999;159:1726-30.

22. Wakabayashi T, Ohno H, Hayakawa Y, Kawashima A, Sawabu N. Primary biliary cirrhosis associated with type A gastritis and chronic thyroiditis. J Gastroenterol 1999;34:415-9.

23. Asante MA, Mendall MA, Ballam L, Morris J, Northfield TC. Relationship between Helicobacter pylori, gastric parietal cell antibodies and heat shock proteins. Eur J Gastroenterol Hepatol 1999;11:1365-70.

24. Annibale B, Aprile MR, D’Ambra G, Caruana P, Bordi C, Delle Fave G. Cure of Helicobacter pylori infection in atrophic body gastritis patients does not improve mucosal atrophy but reduces hypergastrinemia and its related effects on body ECL-cell hyperplasia. Aliment Pharmacol Ther 2000;14:62534 .

\section{Book Review}

\section{Hoffman GS, Weyand CM, editors: Inflamma- tory Diseases of Blood Vessels, 840 pp, New York, Marcel Dekker, Inc., 2001 (\$225.00).}

This book is divided into three major sections: 1 ) scientific basis for health and disease; 2) primary vasculitides; and 3 ) secondary vasculitides. The first part is essentially an attempt to understand the pathophysiology of vasculitis, beginning with an overview and continuing with in-depth analyses of multiple putative factors, including endothelial cell adhesion molecules, extracellular matrix, autoantibodies, T-cells, neutrophils, oxygen metabolites, cytokines, and Fc receptors. Three chapters are devoted to inflammatory, infectious aspects and cellular immune responses in atherosclerosis. One chapter is devoted to angiogenesis regulation. The final chapter summarizes the animal models of vasculitis. As one can assume, the exact relevance and importance of all of these subjects to human vasculitic syndromes is unknown. Nevertheless, this section sets forth a reasonable approach for analyzing the basis for vasculitis at this point in time. The next section, primary vasculitides, begins with historical per- spectives and continues with general approaches, histopathology, radiological imaging techniques, and then deals with the various vasculitic syndromes. There are 23 chapters in this section, which forms an important source area for clinically useful and relevant material. Many of the authors are well known to those interested in vasculitis. Finally, the book finishes with a section on secondary vasculitis that includes 14 chapters. This section, again, is clinically relevant, for the most part, and presents a comprehensive analysis of the area.

This volume stands out, in my experience, as having the most chapters (52) and authors (90) of any book on the subject of vasculitis that I have ever encountered. This, of course, means that there is some redundancy and variation of quality. However, as an overall source book from all standpoints, this book is an outstanding contribution and is highly recommended.

\section{Seymour Rosen}

Beth Israel Deaconess Medical Center

Boston, Massachusetts 